\title{
Assignment Design and its Effects on Japanese College Freshmen's Motivation in L2 Emergency Online Courses: A Qualitative Study
}

\author{
Murod Ismailov $^{1}$ (D) $\cdot$ Yuichi Ono $^{1}$
}

Accepted: 2 April 2021/Published online: 14 April 2021

(C) De La Salle University 2021

\begin{abstract}
Unlike conventional distance learning, the COVID-19-induced emergency online learning environment has resulted in students experiencing prolonged social isolation and anxiety, thereby creating additional barriers to their motivation to learn. Studying under these conditions influences students' motivation to complete and turn in course-related assignments, especially newly enrolled students taking the English reading online courses as second language learners (L2). The aim of this qualitative study is to examine various factors influencing Japanese college freshmen's $(n=80)$ motivation when completing graded online assignments as part of asynchronous English reading courses held during the COVID-19 pandemic. The post-course survey of students from three separate classes was used to capture a detailed panorama of learner motivation. Results from an inductive content analysis of responses indicated that higher levels of motivation were strongly associated with assignments that facilitated learner autonomy, social interaction, personal interest, and practical utility of the task. Conversely, decreased motivation appears to be strongly associated with assignments reinforcing the perception of high difficulty, personal inefficacy, and cognitive overload. These findings are consistent with studies examining online learners' motivation in the pre-pandemic period. This study found that intrinsic motivation plays an explicit role in enhancing learners' engagement with instructional materials. Researchers
\end{abstract}

Murod Ismailov

ismailov.murod.gm@u.tsukuba.ac.jp

Yuichi Ono

ono.yuichi.ga@u.tsukuba.ac.jp

1 Center for Education of Global Communication (CEGLOC), University of Tsukuba, Tsukuba, Japan recommend that, especially during emergencies such as a pandemic or major crisis, teachers should deliberately and extensively employ strategies to enhance the motivational appeal of instructional materials and assignments. When designing online assignments for freshman courses, special attention must be paid to psychological (autonomy, utility, relevance), cognitive (information overload), social (relatedness, interaction), and environmental (an emergency, uncertainty, isolation) conditions of learning.

Keywords Assignment design - Learner motivation ·

L2 - Emergency online learning · COVID-19 .

College freshmen

\section{Introduction}

The COVID-19 pandemic has had an unprecedented impact on many aspects of human life, exceptionally affecting educational institutions and practices worldwide. According to the UNESCO data, as of early April 2020, the spread of novel coronaviruses has caused the closure of educational establishments in 193 countries affecting over 1.5 billion learners globally or $91.2 \%$ of total enrolled students (UNESCO, 2020). Despite considerable efforts to re-open schools taking place across primary and secondary education under social distancing conditions, as of this writing, most universities and colleges in Japan continue to suspend all face-to-face classes. Instead, they implement a variety of remote learning methods (MEXT, 2020) with limited access to college campuses (Ono, 2020).

Online learning methods in a variety of forms have been used for many years. However, the key difference between teaching conventional courses and emergency online courses necessitated by the global health crisis (Hodges 
et al., 2020) is the speed and urgency with which transition is expected to take place and the effect of other social and psychological factors on this process (Green et al., 2020; Williamson et al., 2020). For example, the suspension of face-to-face classes at Japanese universities caused anxiety to a significant number of faculty and students due to the lack of skills and prior experience in using online platforms (O'Donoghue, 2020), combined with the increased volume in workload, prolonged self-isolation at home, health concerns over the spread of the novel coronavirus, and economic concerns for the unknown circumstances of the future ahead (Japan Times, 2020). In particular, these challenges have potentially more serious effects on inexperienced freshmen and their attitude to online learning during the pandemic

Students' attitudes towards online learning are closely related to intrinsic motivation to satisfy curiosity and extrinsic motivation to engage with the course material (Kim and Frick 2011). It is suggested that the instructional design of self-directed online learning environments can play an important role in enhancing learners' experiences (Ferrer et al. 2020). Given that instructional strategies are key for stimulating student motivation and engagement during online learning, previous studies suggested that online assignments should (1) provide learners with relevant and useful content, (2) incorporate multimedia presentations with hands-on and real-world activities, (3) create collaborative learning opportunities using online communication tools, and (4) match content difficulty with the learners' zone of proximal development (Kim and Frick, 2011; Martin and Bolliger, 2018).

In addition to the design of online assignments, formative assessments conducted online through group discussions and interviews (McKenzie et al., 2013), quizzes (Zainuddin et al., 2020), and tests (Chen, Jiao and Hu, 2021) have been positively associated with student engagement and learning performance (Dalby and Swan, 2018). These findings have implications for how learners can be engaged in an online course, and the instructors' need to design online learning environments that foster student engagement and interest. Moreover, these assignment designs and formative assessment strategies are consistent with the Attention-Relevance-Confidence-Satisfaction (ARCS) theoretical model that links instructional design and learner motivation (Keller, 1987). They more generally link with the Expectancy-value theory (EVT) of motivation, suggesting that students' expectations for success and subjective task values predict their motivation to complete a given assignment (Rosenzweig et al., 2019; Zhang and Bae, 2020).

Furthermore, it is important to consider factors that decrease learners' motivation, especially first-time online learners. The most recent study involving over a thousand
Japanese freshmen explored their online learning experiences during the COVID-19 pandemic (Ono, 2020) looking at environmental and instructional factors, such as network access and comfort, the duration of study, time for assignment completion, and style of online lesson delivery. The study found that the instructional design of online courses was significantly correlated with the first-year Japanese students' higher levels of fatigue. Other studies also indicated that fatigue from information overload make it difficult for learners to focus their available cognitive resources on tasks associated with learning, and often causes decreased motivation and disengagement (LePine et al., 2004; Pintrich et al., 2014). According to cognitive load theory, information overload is negatively associated with students' motivation to learn by impeding their attention to the course material and assignments (Hartley, 1999).

Online assignments designed by teachers have a major effect on how students approach online learning. However, the nature of this interaction has not been explored qualitatively to date, in the context of online learning involving Japanese freshmen, nor on the current understanding of emergency online learning during the COVID-19 pandemic. This study contributes to the empirical and the theoretical understanding of the mechanisms that link assignment design and freshmen motivation within an asynchronous online learning environment, and by accounting for environmental conditions related to the pandemic situation.

\section{Literature Review}

Motivation in the academic setting is the process whereby goal-directed activity is instigated and sustained (Pintrich et al., 2014) as well as determined by students' choices to engage, make an effort, and persist in the process of learning (Dörnyei and Ushioda, 2011; Hartnett, 2016). Over the past decade, many studies have been undertaken to examine what motivates students to perform tasks in both online and face-to-face learning environments. Many of these studies have employed theoretical models and constructs, including expectancy-value theory, self-determination theory (SDT), self-efficacy, and the ARCS model.

Expectancy-value theory was developed to explain how individuals' expectancies and values affect their motivation to pursue certain tasks and activities (Atkinson, 1957; Eccles and Wigfield, 2002; Hulleman and Barron, 2016). According to the Expectancy-value theory, two main factors determine students' motivation to learn including how well they expect to perform a task and how much they value their outcome of the assignment completion (Hidi et al., 2019). Motivation theorists have described three 
forms of perceived task values: intrinsic value, which is defined as the enjoyment students experience from doing a task (e.g. 'I really like mathematics'); attainment value, which indicates the importance of the assignment for selfworth (e.g. 'I am able to solve this equation'); and utility value defined as practical usefulness of the task for future goals (e.g. 'Mathematics is important for my future job') (Trautwein et al., 2019). One recent study suggested that among all three values, personal relevance and utility value are more predictive of students' interest and performance when completing course assignments (Hulleman and Barron, 2016).

Self-determination theory (SDT), in contrast, posits that the attainment of autonomy, competence, and relatedness are key determinants of motivation to learn and perform tasks (Ryan and Deci, 2000; Hsu et al., 2019). It is not coincidental that the self-determination theory, with its inclination towards self-growth and personal development, has played an important role in invigorating scholarly debates on intrinsic and extrinsic motivation within the educational context. These studies show, for example, that when driven by internal rewards that are naturally satisfying, intrinsically motivated learners generally demonstrate persistence and high qualifications (Rothes et al., 2014). When learning online, they demonstrate a deeper understanding of the course material (Hoskins and Van Hooff, 2005) and exhibit lower attrition rates (Kim and Frick, 2011; Fryer et al., 2014). In addition, some studies suggested that intrinsic motivation is associated with greater exploration of the learning environment rather than higher levels of achievement (Martens et al., 2004).

On the other hand, extrinsically motivated learners also produce high levels of engagement and achievement. According to Deci and Ryan, (2000), extrinsically motivated learners display introjected regulation (when they want to avoid shame or guilt) and external regulation (when they want to obtain positive outcomes or avoid negative ones). Studies have shown that extrinsically motivated students exhibit persistence in completing a greater number of online courses (Johnson et al., 2015) and show better engagement with the course material (Sansone et al., 2011). Furthermore, they have better performance and lower attrition rates when given autonomy (Patron and Lopez, 2011).

Autonomy plays a key role in motivating learners because of its volitional (self-endorsed) functioning (Ryan and Deci, 2000). From this point of view, autonomy supports motivation and engagement by promoting personally valued interests and needs. As a basic psychological need (Ryan and Deci, 2000), autonomy is instrumental in environments where learners have the freedom to make decisions and choose their preferred course of action (Patall and Hooper, 2019). Autonomy further highlights the importance of provision of choice, which may lead to student motivation and positive learning outcomes (Patall et al., 2013). Studies show that a higher level of autonomy is positively associated with learners' motivation in online learning. For example, several studies have shown that the more the autonomy learners have during online learning (i.e. the freedom to control pace and timing of learning), the higher the levels of motivation and satisfaction they exhibit (Abuhassna et al., 2020).

The other two components of motivation from the viewpoint of the self-determination theory are competency (self-efficacy) and relatedness. Although self-efficacy is usually considered part of social cognitive theory (Bandura, 1997), it may be linked to self-determination theory's competence construct. In academic contexts, self-efficacy refers to learners' personal judgements about their ability to learn, develop skills, or comprehend the material. Thus, self-efficacy may explain students' efforts and willingness to perform a task, their emotional self-regulation, and coping strategies (Bandura, 1997; Usher, 2016). Another component, 'relatedness' refers to the experience of social connections and caring with others. Feelings of social presence and social connectedness with peers and instructors have shown to have a positive motivational effect on online learners (Xie et al., 2006; Rovai et al., 2007). With the inclusion of social navigation, when learners obtain clues about what matters to other online participants, social presence and social connectedness constitute the social ability of online learners (Picciano, 2002; Laffey et al., 2006).

Another useful model to consider is the motivational design of instruction or the ARCS model (Keller, 1983). This model focuses on improving the motivational appeal of instructional materials, including course assignments and tasks. The difference between this model and other theories of motivation is that ARCS uses four conceptual categories that characterise human motivation (Attention, Relevance, Confidence, Satisfaction) to develop a set of strategies to improve the motivational appeal of instruction (Keller, 1987). In terms of assignment design, this model promotes the instructional techniques that attract learners' attention by arousing their interest and sense of the relevance of tasks at hand. For example, studies of online learning posit that during activities and assignments the engagement levels of learners who are personally interested in the topic are higher (Xie et al., 2006). Personal interest is enhanced when online environments provide learners with greater autonomy (Moos and Marroquin, 2010) and conceptual scaffolding (Moos and Azevedo, 2008). In addition to having a personal interest in a topic, students are more likely to be motivated to learn online when they are engaged with content that is relevant and useful to them, especially through authentic assignments 
that simulate real-world situations or that allow them to incorporate what they have learned into their lives (Kim and Frick, 2011; Merrill, 2002). Students who are motivated to learn may not necessarily find assignments pleasurable or exciting, but they may find them meaningful and of practical relevance (Brophy, 2008). When exposed to information-abundant online contexts, learner interest diminishes over time without novel stimuli (Moos and Marroquin, 2010), authentic activities may reinvigorate a learner's interest and engagement. Herrington et al. (2004) suggested that authentic activities - often flexible and open to multiple interpretations-may well be within the learners' zone of proximal development (Vygotsky, 1978). The zone of proximal development is believed to be the boundary between the learners' capacity to perform a certain task independently, and their capacity to perform a task only through receiving assistance or scaffolding from an instructor or peer (Podolskiy, 2012).

In addition to the aforementioned motivational constructs, one additional factor also plays a role in decreasing students' motivation to learn. Studies found that motivation is negatively affected when students feel overwhelmed by the mental effort necessary to learn (Morrison and Anglin, 2005; Pintrich et al., 2014). In other words, cognitive overload and the perceived difficulty of assignments decrease learners' motivation to complete tasks during online learning. This is consistent with research suggesting that information overload can decrease students' motivation to learn by constraining their attention to the instructional material (Hartley, 1999). Information overload also correlates with high drop-out rates in the first weeks of an online course, especially among students with no prior experience of learning online (Tyler-Smith, 2006). It has also been established that the perceived difficulty of an online assignment causes anxiety and negatively affects student motivation (Kim and Frick, 2011) because the task is outside the learner's zone of proximal development (Vygotsky, 1978).

The extensiveness of psychological factors and constructs found in motivational research led to the development of perspectives that emphasise the situated nature of motivation (Turner and Patrick, 2008). Consistent with this, this review of the literature shows that motivation in an online learning setting is a complex and situation-dependent phenomenon. The degree of complexity and situatedness may be influenced by many factors (Hartnett, 2016), including online instructional practices, assignment designs, assessment techniques as well as the social and practical value of learning.

\section{The Aim of the Study and Research Questions}

The aim of the current study is to qualitatively examine various factors influencing Japanese college freshmen's motivation when completing online assignments during an asynchronous English reading course conducted during the COVID-19 pandemic. The study was guided by the following research questions:

1. What factors influence students' motivation and interest to work effectively on assignments for asynchronous English reading courses, and which assignments are perceived as motivating?

2. What factors influence students' decreased motivation and disengagement when working on assignments for asynchronous English reading courses, and which assignments are perceived as not motivating?

3. What are the theoretical and practical implications of instructional design for online learner motivation and engagement?

\section{Methodology}

\section{Participants}

The current research utilised the convenience availability sample of three separate first-year undergraduate student classes $(n=80)$, predominantly Japanese $(95 \%)$, enrolled in English reading skills online courses at a large public university in Japan. There were $37(46.3 \%)$ men and 43 $(53.7 \%)$ women. Only 4 students $(5 \%)$ were international, and none of them were native speakers of English. The students were enrolled in a fully asynchronous online course during the spring semester (May-August) of 2020, taught through the learning management feature of the Microsoft Teams application. The English reading skills course is a compulsory freshman course that is taken by students from various academic majors. To qualify for credit, students must complete the course during both spring and fall semesters. Students who completed and returned the post-course surveys belonged to media arts, science and technology (22.5\%), humanities (32.5\%), comparative culture $(28.8 \%)$, Japanese language and culture $(6.2 \%)$, and Chemistry $(10.0 \%)$. In addition, the postcourse survey revealed that $57.6 \%$ of the students attended between 16 and 20 online courses weekly, whereas $17.8 \%$ of students had 21 or more online courses to take on a weekly basis during the pandemic. Students who attended 15 or less online courses weekly constituted $24.6 \%$ of the total number of participants. 


\section{Procedures}

The core curriculum of the English reading skills course consisting of 15 weekly modules was originally designed for a face-to-face learning environment with the goal of teaching students English reading comprehension strategies and techniques. However, due to the rising number of coronavirus infections in Japan, around the middle of March 2020, the authors' institution made an unprecedented decision to carry out all courses via distance learning platforms. The use of an asynchronous or on-demand style of online instruction was recommended university wide to prevent low participation and high attrition rates due to poor network connectivity. The instructors created nine on-demand video lessons using the Microsoft Stream to teach content. The researchers kept the original structure of the syllabus containing one introductory nongraded session, eight graded assignments with deadlines, five non-graded review sessions, and one course wrap-up session. Most assignments from the original syllabus designed for face-to-face instruction were deemed compatible with asynchronous online learning as well as the theoretical assumptions that inform the current study. In addition, assignments \#1 and \#3, as shown in Table 1, were added to the syllabus to fit the online learning environment and to address the theories of online learning related to joy, perceived utility (assignment \#1), and social interaction (assignment \#3).

Due to the on-demand nature of the instruction, the word 'assignment' is used rather flexibly in this study to denote homework and/or classwork, depending on the time the students were completing it. In addition, in this study, we focused specifically on graded assignments because it can help shed light on both intrinsic motivation and extrinsic motivation for completing them. Both researchers took part in the assessment of the assignments submitted by their respective groups, providing their students with detailed feedback as well as regular guidance throughout the course using the Microsoft Teams app chat and email facility.

\section{Data Collection}

A semi-structured post-course question guide (see 'Appendix 1' section) was developed by the researchers based on motivation theories and constructs reviewed in the previous section (e.g. Bandura, 1997; Eccles and Wigfield, 2020; Keller, 1987; Ryan and Deci, 2000). The purpose of the questionnaire survey was two-fold. Firstly, the questionnaire enabled us to gather student views on the assignment design of the online course and various factors influencing students' motivation when working on the course tasks. Secondly, considering the uncertainty over the spread of COVID-19 and the possibility that the classes would continue to be held online in the following fall semester as well, the survey results would allow the authors to redesign the assignments based on students' feedback to provide a better learning experience to the same group of students. The purposes of the survey were clearly explained to all participating students via post-course email, group chat message on the Microsoft Teams application, and as a preamble on top of the questionnaire form. With the aim of increasing the validity of students' responses, researchers

Table 1 An overview of assignment design for the English reading online courses

\# Module's topic Assignment description

1. Find the essential information

2. Find the topic sentence

3. Find the main idea

4. Compare and contrast information

5. Vocabulary in context

6. Identify cause and effect

7. Distinguish facts from opinions

8. Identify the order of importance
Watch a video titled 'Why One Man Owns 2371 Cell Phones' and write down fifteen 5W1H questions to find out the key information.

Please read the passage titled 'A Letter to a Pet-sitter' and answer the following five questions using the online quiz.

Read the article 'Does Japan Get Enough Sleep'? and, based on the main idea, conduct an online interview of your classmates.

Write a $500+$ word free-style essay by comparing or contrasting two pieces of information (e.g. your favourite book, manga comics, movie, etc.).

Take a 20-question online quiz.

Mini-task \#1: Complete the following sentences with their likely effects.

Mini-task \#2: Complete these sentences with possible causes.

Mini-task \#3: Match the causes with their likely effects.

Read chapter one of the book 'igital Minimalism'a . Summarise the main idea. Identify the key information, one or two opinions and facts, and describe $2-3$ new vocabulary discovered.

Read chapter one of the book 'Rich Dad, Poor Dad'b and complete the KWL Chart.

${ }^{\mathrm{a}}$ Newport, C.C. (2019). Digital Minimalism: Choosing a Focused Life in a Noisy World. New York: Portfolio/Penguin; ${ }^{\mathrm{b}}$ Kiyosaki, R. T. (2017). Rich Dad, Poor Dad: What the Rich Teach Their Kids About Money That the Poor and Middle Class Do Not! (2nd ed.). Scottsdale: Plata Publishing. 
emphasised through all three media that the students' unbiased and detailed responses would help instructors understand and address critical issues related to course instruction and assignments in the following semester.

The questionnaire was sent to students 1 week after the final grades were announced to eliminate the fear that their responses might influence instructors' subjective end-ofcourse evaluation. The questionnaires were distributed in electronic format using the Microsoft Forms application, which allowed the creation of both open-ended and multiple-choice questions. The use of this format was determined by the convenience of participating in the survey using both mobile and desktop devices. The examination of emergency online classroom experiences is, as argued by Ono (2020), better served by using open-ended questionnaires, rather than statistical analyses, to render a deeper level of detail and insight into learners' engagement in the time of the COVID-19 pandemic. Eighty out of 91 students $(87.9 \%)$ have completed and returned the postcourse survey.

\section{Data Analysis}

By choosing a combination of thematic and narrative analyses, researchers explored and conceptualised human experience as represented in the post-course survey. Following Silverman (2004), the collected survey responses were analysed using an inductive content analysis approach. The researchers focused on examining the entire experience as well as fragmenting it into discursive units or thematic categories (Josselson 2011). In the first stage of the analysis, the researchers examined the students' responses to recurring instances of a general nature, followed by a more systematic identification and grouping of such instances across the entire dataset through an open coding system. As a result, researchers identified two main themes - the assignment that motivated the most and the assignment that did not motivate at all. In the second stage, the codes related to each main theme were identified and grouped into categories. According to MacKinnon et al. (2007), this approach allows researchers to identify mediating factors that influence the strength of the relationship between the independent variable and the determinant.

Initially, the coding presented a challenge to the researchers because many of the responses contained multiple units of meaning related to different categories under the same theme. For example, in the following case, 'The matching assignment to identify cause and effect relationships motivated me because the assignment was useful to improve my grammatical skills in English. By making a sentence by myself, I was able to imagine freely and creatively. I had lots of fun doing this assignment'! (S32). This case contains units of meaning matching three different categories (perceived practical utility, learner autonomy, and sense of joy and/or discovery) all under the theme of motivating assignments. To ensure the reliability of the content analysis to the extent that both researchers agreed on the coding of the content of interest and applied the same coding procedure (Burla et al. 2008), the authors engaged in an intercoder reliability test. A total of 156 open-ended responses were analysed, producing 185 units of meaning. Ten cases involved a disagreement between the researchers when including certain units of meaning into specific categories. The test resulted in $94.6 \%$ intercoding agreement on the analysed content. The researchers did not edit the student responses for grammatical correctness before or during the coding stage to avoid miscoding the data.

\section{Results}

\section{Q1: What Factors Influence Students' Motivation and Interest to Work Effectively on Assignments for Asynchronous English Reading Courses, and Which Assignments are Perceived as Motivating?}

Content analysis of the students' responses identified ten themes associated with motivation and interest when completing online assignments (see Fig. 1). The primary focus of the content analysis was to present the range of factors affecting students' motivation to complete courserelated assignments rather than to highlight some factors over others. These themes included learner autonomy, social interaction, personal interest in the topic, perceived practical utility, meaningful activity, self-efficacy, sense of joy and/or discovery, authentic activity, outside pressure, instructor guidance, and/or feedback. Three themes, learner autonomy, social interaction, and personal interest in the topic of assignment, were more frequently mentioned by freshmen.

Among these three themes, a significant number of responses, as shown in Fig. 1, emphasised the importance of autonomy and the degree of freedom that students were given to complete a particular task. One student's remark exemplifies responses in this category: 'I could write the essay freely. In most of the assignments in this semester, the content was about what we learned. Reviewing is, of course, very important. But it was too much for me. So, I could feel relaxed and interested in writing a free-style essay' (S23). The students' perceived autonomy and control seemed to be associated with various abilities. Examples included the following: self-worth-'It was because I can write what I like and I can express myself freely' (S11); perseverance-'To write a $500+$ word essay is a 


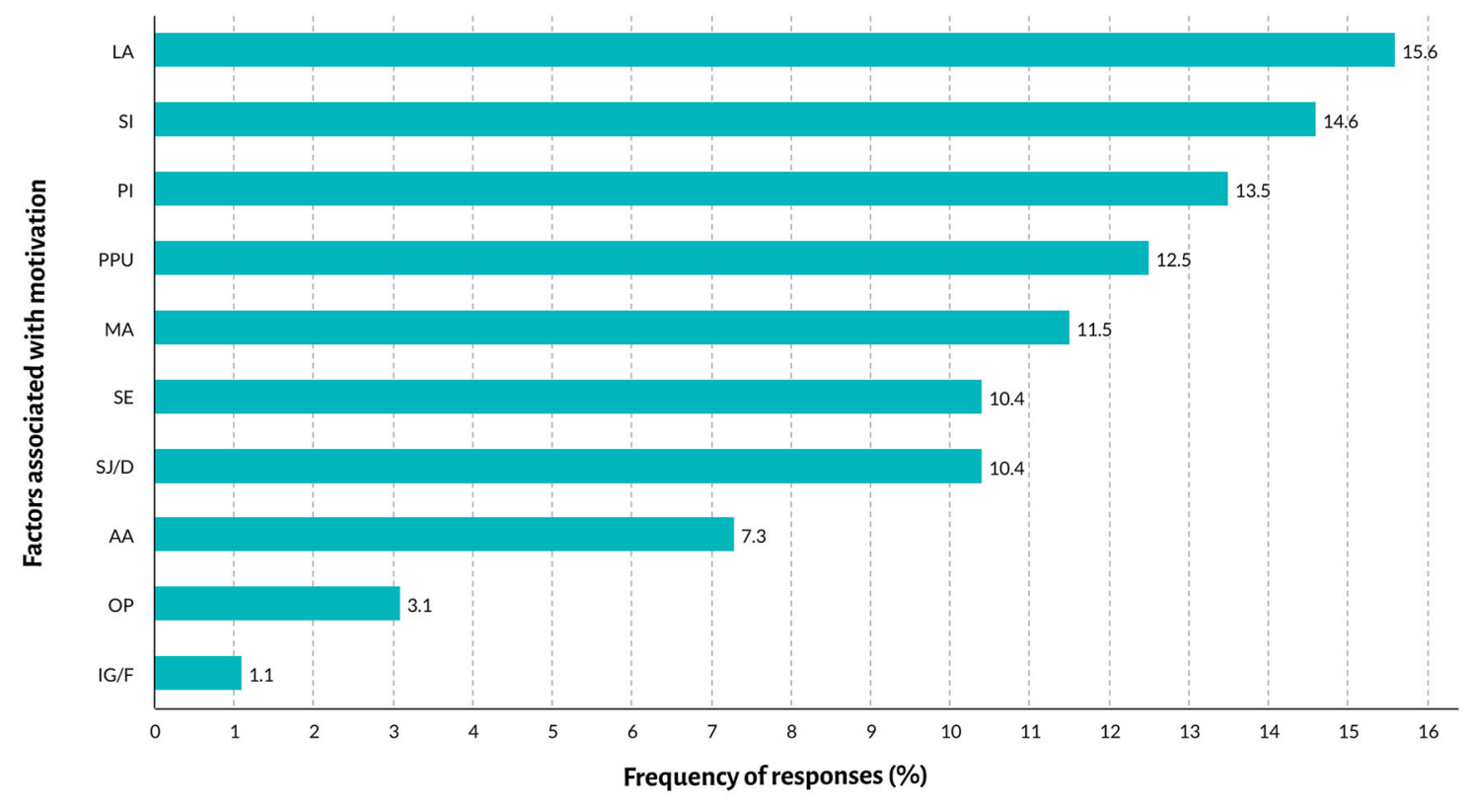

Key: $\mathrm{LA}=$ Learner autonomy; $\mathrm{SI}=$ Social interaction; $\mathrm{PI}=$ Personal interest in the topic; $\mathrm{PPU}=$ Perceived practical utility; $\mathrm{MA}=\mathrm{Meaningful}$ activity; $\mathrm{SE}=$ Self-efficacy; $\mathrm{S}] / \mathrm{D}=$ Sense of joy and/or discovery; $A A=$ Authentic activity; $O P=$ Outside pressure; IG/F=Instructor guidance and/or feedback.

Fig. 1 Factors increasing motivation to complete online assignments

hard task for me so it took me a long time to complete it, but because the essay topic was not specified, I enjoyed writing while thinking about the theme' (S74); and cognitive presence- It is interesting to think about the structure and expressions to clearly tell readers about the charm of what I like' (S63).

Social interaction was mentioned in student responses when describing the lack of opportunities for face-to-face socialisation with peers during pandemic-induced remote learning. One response is typical in this category: '...because I really enjoyed talking with my friends in English, and it was an extremely rare chance for me to talk with my new friends from the University during the epidemic' (S2). Other students mentioned various useful aspects of online peer-to-peer learning: 'They [online team members] were not from the school of science and engineering which I belong to. Thus, we could exchange information about classes in other departments' (S55). Another student added that 'it was refreshing to talk to other people and do an assignment. It took a lot of time, but it was fun' (S11).

Responses under the third most frequently mentioned theme were characterised by students' high level of personal interest, even though some learners initially perceived these assignments as difficult or challenging. One student's response can illustrate this sentiment: 'I had a hard time coming up with more than 500 words for the essay, but I was able to write about something that I like, so it was much more motivating for me than just writing about something I am not interested in' (S4). Another student said that 'the book Rich Dad, Poor Dad itself was interesting. I usually do not like reading assignments because it is obvious that it takes much time. However, this assignment luckily had a topic that I was interested in, so I enjoyed it' (S18).

These three popular themes were followed by four other themes, perceived practical utility, meaningful activity, self-efficacy, and sense of joy and/or discovery, which many respondents mentioned in the survey. Responses under the theme perceived practical utility suggested that some assignments provided the students with an opportunity to gain new knowledge. One student stressed that the main reason for her active participation in an online interview task about sleeping habits in Japan had to do with her desire to learn something useful: 'I wanted to know about sleep because I want to know how many hours we should sleep' (S44). Other students' responses highlighted the opportunity to practise academic and language skills: 'At first, I didn't want to do this assignment. But then I thought I could improve my vocabulary. The content of the sentences was interesting, so it was so motivating for me' (S71). Another student explained 'I chose a digital game as the theme of the essay. This assignment allowed me to study and research more and more about my favourite topic. I gained new knowledge through comparison' (S20).

Responses also indicated that several students saw online assignments as meaningful experiences that created a sense of self-worth, confidence, and identity: 'I was able to realise that I could express myself better in English than 
in high school, and that made me feel that my university studies were meaningful' (S80). Other students viewed online assignments as an achievable challenge, suggesting that the theme of positive 'self-efficacy' was evident in students' responses, such as this one: 'This assignment took more time compared to other assignments in this course, but I was confident about the quality of my writing and I felt a sense of accomplishment' (S13). In addition, many students associated their motivation to perform a task with a sense of enjoyment and discovery. One student's response is typical: 'I really enjoyed it [writing a 500-word free-topic essay] very much because describing how my favourite things are amazing was so pleasant, and I was preoccupied with my favourite things while doing this task. I came to like those more through this assignment' (S28).

The students' responses related to authentic activity, outside pressure, and instructors' guidance and feedback have been mentioned comparatively fewer times. For example, only a few respondents mentioned outside pressure, such an as approaching deadline, fear of causing trouble to fellow teammates, or course grades. One student said 'I felt more responsible to complete this assignment because if I did not submit it, the time my classmates kindly spared for the [online] interview would be wasted' (S21). Similarly, a few students seemed pleased by the course instructor's guidance and feedback: 'It was also good to get feedback on the assignment' (S16).

A more detailed look into students' responses revealed that the online assignments, such as writing a 500-word free-style essay by comparing or contrasting two pieces of information (e.g. a favourite book, manga comics, movie, etc.), or conducting a virtual interview of classmates after reading a newspaper article, were perceived as motivating by many students (see Fig. 2). Students who mentioned these assignments were more likely to mention learner autonomy, social interaction, personal interest in the topic, and perceived practical utility as their primary motivators. In contrast, assignments, such as taking a short and long online quiz or reading a book chapter and analysing its content, appear to be considerably less motivating.

\section{Q2. What Factors Influence Students' Decreased Motivation and Disengagement, When Working on Assignments for Asynchronous English Reading Courses, and Which Assignments are Perceived as not Motivating?}

Similarly, the researchers conducted an inductive content analysis of the students' responses to examine themes associated with decreased motivation and disengagement when given online assignments. Coincidentally, the analysis facilitated the identification of ten themes (see Fig. 3), including perceived high difficulty of task, low self- efficacy, cognitive overload, outside pressure and/or obstacle, perceived lack of meaning and/or learning effect, lack of personal interest, unclear and/or insufficient instructions, fatigue, lack of feedback on completed assignments, and perceived lack of incentives. From these ten factors, students mentioned perceived high difficulty of task, negative self-efficacy, and cognitive overload more frequently.

For example, the perceived high difficulty of a task appears to hinder the effective completion of the task by many students. One typical student response in this context was 'I am not very good at reading in English, and the chapter was too long for me. So, I hesitated to read and do the work' (S49). A large number of responses highlighted the low self-efficacy associated with students' perceived lack of necessary knowledge and skills to complete an assignment: 'I could not figure out what was What I Know by simply reading the chapter's title that I had never seen before' (S7). In addition, many students complained about cognitive overload related to their perception of the excessive amount of work and time required: 'I was reluctant to start reading the chapter due to the amount of time required to finish it and the theme of this assignment' (S19).

Such factors as outside pressure and/or obstacle ('It was difficult to adjust our [virtual teamwork] schedule because we watched the video lesson and read the document during the time of this class. So, we had to make the meeting time on the days we did not have other classes, such as on Sunday' S15), perceived lack of meaning and/or learning effect ('I thought the book Rich Dad, Poor Dad was not the correct option to choose to make us make the KWL Graph. That book tells us the opinion of that author, so we could not find any facts' S31), and lack of personal interest ('It was least motivating for me because the [chapter of the] book Digital Minimalism had a long content [sic] and was not really interesting for me' S70) have also been considered by students as not motivating.

Lastly, significantly few students believed that such factors as unclear and/or insufficient instructions ("Actually, I thought that the instruction was not enough. When I started the assignment, I got confused and did not understand what to do' S32), fatigue ('It was a very long chapter for me. I was so tired to read, and I could not fully understand the story' S9), lack of feedback on completed tasks ('However, I chose this one because there was an unclear criterion for the correct answers compared to other assignments. I wish I could learn more about why those answers were correct' S72), and perceived lack of incentives ('We had a lot of work to do, but there were not many points allocated for this assignment' S23) negatively affected their motivation to perform a task. 


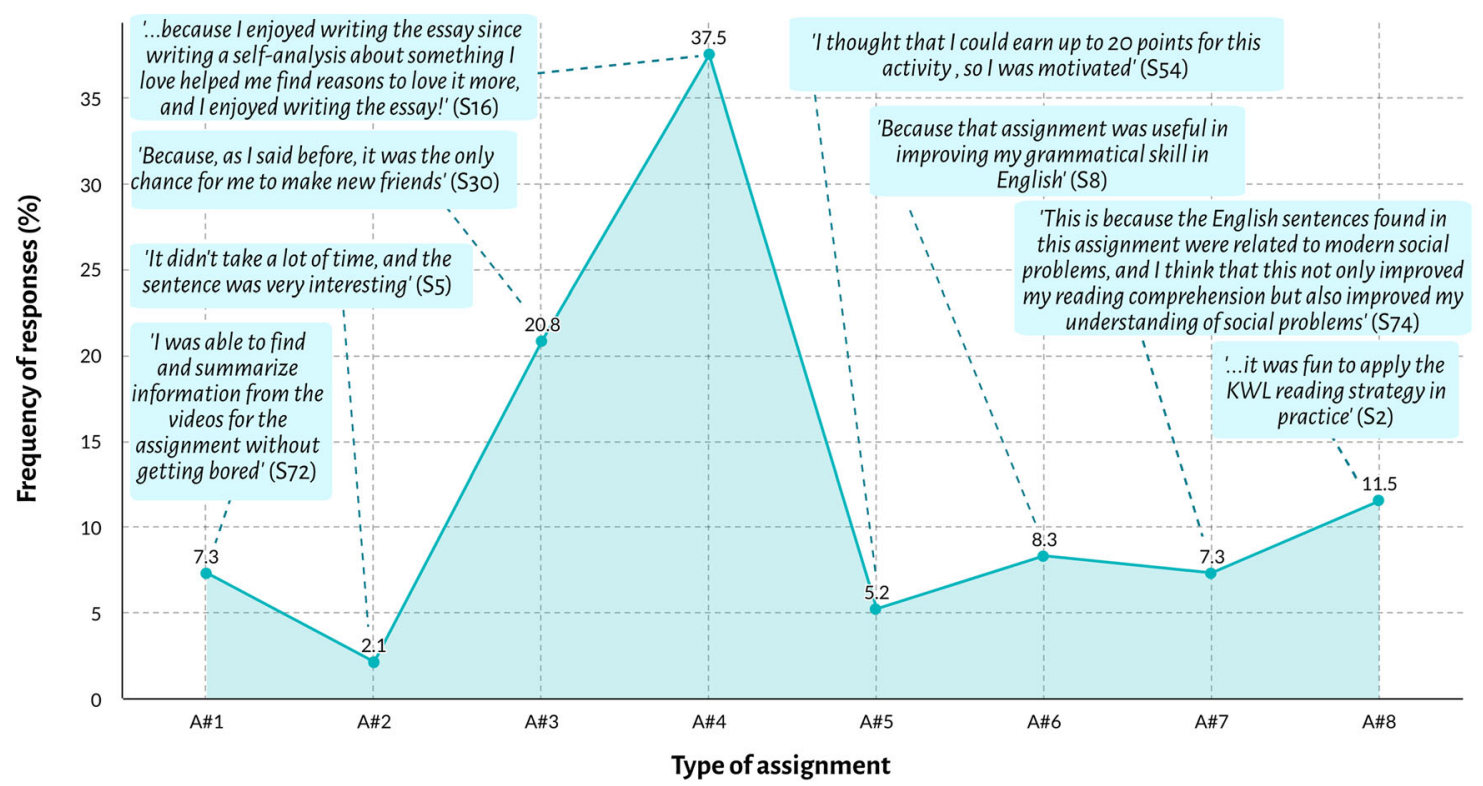

Key: $A \# 1=$ Watch a video and compose 15 questions; $A \# 2$ = Take a short 5-question online quiz; A\#3 = Read an article and conduct a virtual interview of your teammates; $A \# 4$ = write a $500+$ word free-style essay by comparing or contrasting two pieces of information; A\#5: Take a long 20 question online quiz; A\#6 = Matching task related to the topic of 'cause and effect'; A\#7 = Read and analyse a chapter of the book 'Digital Minimalism'; A\#8 = Read a chapter from the book 'Rich Dad, Poor Dad' and complete a KWL graph (what I Know, what I Want to know, what I have Learned).

Fig. 2 Assignment types perceived as motivating

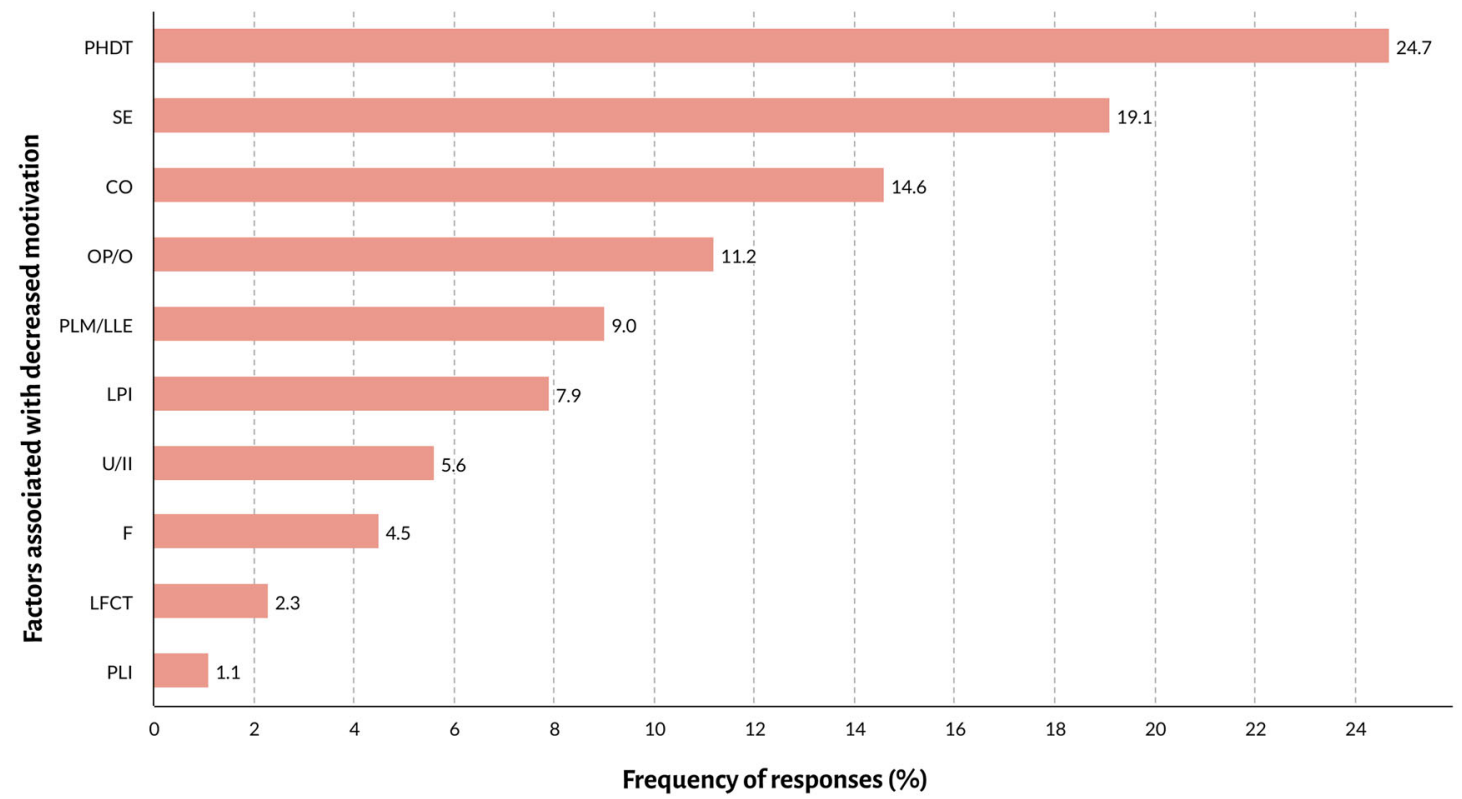

Key: $\mathrm{PHDT}=$ Perceived high-difficulty of task; SE = Self-efficacy; $\mathrm{CO}=$ Cognitive overload $; \mathrm{OP} / \mathrm{O}=$ Outside pressure and/or obstacle; PLM/LLE = Perceived lack of meaning and/or low learning effect; $L P I=$ Lack of personal interest; U/II = Unclear and/or insufficient instructions ; F = Fatigue; LFCT $=$ Lack of feedback on completed tasks; PLI = Perceived lack of intensives.

Fig. 3 Factors decreasing motivation to complete online assignments

As for the specific assignments (see Fig. 4), notably, many respondents mentioned that reading a book chapter from Digital Minimalism, summarising its main idea, and identifying key information and new vocabulary were associated with their experiences of decreased motivation.
Less frequently, respondents mentioned the other seven assignments, including writing a 500+ word free-style essay, watching a short YouTube video, and comprising essential questions as well as being less motivating and interesting. 


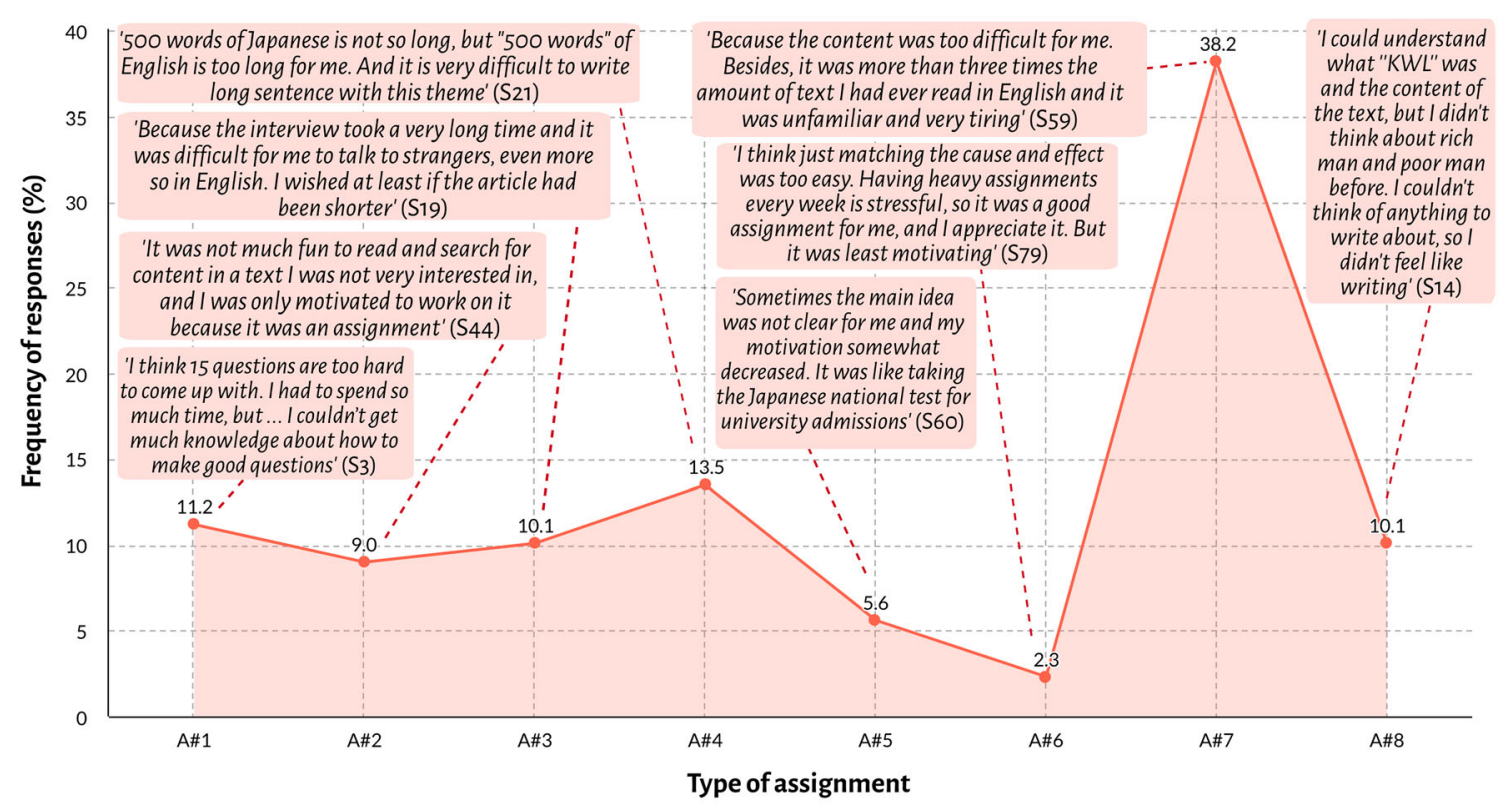

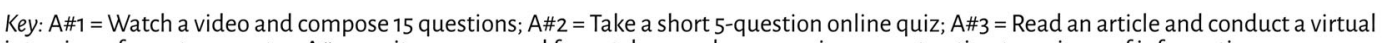
interview of your teammates; $A \# 4=$ write a $500+$ word free-style essay by comparing or contrasting two pieces of information;

A\#5: Take a long 20-question online quiz; $A \# 6=$ Matching task related to the topic of 'cause and effect'; A\#7 = Read and analyse a chapter of the book 'Digital Minimalism'; A\#8 = Read a chapter from the book 'Rich Dad, Poor Dad' and complete a KWL graph (what I Know, what I Want to know, what I have Learned).

Fig. 4 Assignment types perceived as not motivating

\section{Theoretical and Practical Implications}

The current study was a qualitatively examination of various factors associated with Japanese freshmen's motivation to work on online assignments during an asynchronous English reading course at the time of the pandemic. The results reported in this study have several theoretical and practical implications for understanding how instructional design affects learner motivation and engagement with online coursework.

The results suggest that many theories of motivation provide useful instruments to explain what kinds of instructional materials and assignments to motivate freshmen to learn online during the pandemic. In the current study, the self-determination theory's analytical constructs have proven helpful in explaining why many freshmen find certain kinds of assignments more motivating and interesting than others. The self-determination theory's autonomy and relatedness constructs were particularly noteworthy in this context. This study also determined that higher levels of freshman motivation were associated with learner autonomy and social interaction. These results are consistent with the existing research on motivation in online learning in pre-pandemic situations, suggesting that online learners are more likely to exhibit motivation when they are given a certain degree of freedom over the content and pace of their learning (Abuhassna et al., 2020; Moos and Marroquin, 2010; Patall et al., 2013; Patall and
Hooper, 2019). Likewise, they are more motivated when given opportunities to interact and socialise with other students through virtual tasks (Hsu et al., 2019; Tu and McIsaac, 2010).

These results suggest that freshmen taking emergency online courses have been strongly affected by intrinsic motives when performing course tasks (Kim and Frick, 2011; Merrill, 2002). Thus, personal interest, enjoyment, freedom of choice, need to socialise during school closure, and social distancing have played important roles. Very few responses reflected learners' motivation from such factors as outside pressure, grades, and fear of failure. In contrast to previous research (Hartnett, 2016), this study has found no significant relationship between the instructor's role and students' motivation to learn, suggesting that in the asynchronous learning environment, the assignments that promote learners' freedom of choice may be positively linked to intrinsic motivation. The researchers are of the view that at the time of major pandemic, or for that matter, any emergency of natural or socio-political character, intrinsic motivation plays a more explicit role in enhancing learners' engagement with instructional materials and tasks.

Along with self-determination theory, expectancy-value theory supports several key findings of this study. For example, the results are consistent with the theory that Japanese freshmen's motivation to perform online tasks was associated with their positive expectations to perform a 
task and how much they valued the outcome of the assignment's completion (Hidi et al., 2019). All three forms of perceived task value (Eccles and Wigfield, 2002; Trautwein et al., 2019) were strongly reflected in freshman responses, including intrinsic value ('I really enjoyed it very much because describing how my favourite things are amazing was so pleasant...' S28), attainment value ('...I was confident about the quality of my writing and I felt a sense of accomplishment' S13), and utility value ('But then I thought I could improve my vocabulary...' S71). Compared to previous research suggesting personal relevance and utility value as more predictive of students' motivation to perform tasks (Hulleman and Barron, 2016), the current qualitative study observed no significant differences among the three forms of perceived task value. Overall, these findings are consistent with previous research indicating that personal interest in the topic and practical utility play key motivational roles in online learning (Brophy, 2008; Xie et al., 2006).

Moreover, this study argues that the intrinsic value of enjoyment/interest, attainment value of self-worth, and utility value or meaningfulness of the experience are related to learners' intrinsic motives more than to extrinsic ones. Thus, the instructional design that promotes these values may likely result in greater learner motivation and engagement. The ARCS Model of Instructional Design (Keller, 1983) is worth mentioning in this context. The design of the assignments in this study and the results of the experiment were found to be compatible with the ARCS model's four constructs (attention, relevance, confidence, and satisfaction). Because this model builds on the expectancy-value theory and several other theories of learner motivation (Keller, 1987), it is not coincidental that freshman participants paid closer attention to tasks that required their self-reflection or independence, or that they found tasks practical and useful. When working on assignments that were within students' zone of proximal development their personal judgements of self-efficacy, confidence, and possibly their satisfaction were also affected.

It is important, as well, to deconstruct factors that led to freshmen's decreased motivation and disengagement. Decreased motivation seems to be closely related to the perceived high difficulty of tasks as well as Japanese students' perception of inefficacy and cognitive overload, preventing their effective work on assignments. We posit that these triggers of students' decreased motivation are closely interconnected. For example, all three could be explained by the lack of direct academic and social interventions aimed at freshmen during the first months of the study. The need for social distancing during the pandemic caused the cancellation of face-to-face freshmen orientation sessions and suspended all in-person tutoring programmes. Students would otherwise have the opportunity to gain foundational knowledge and academic skills and become better familiarised with the differences between studying in high school and in university. Studies on social and academic adjustment of college freshmen (Mudhovozi, 2012; Sasaki and Yamasaki, 2007) demonstrated that this category of students needs extensive institutional and academic support to adapt to college life (Leong et al., 1997). Also, the fact that the students were taking an online course that combined academic skills (i.e. reading proficiency) and language learning (i.e. course taught in English) might have intensified cognitive overload affecting students' self-efficacy (Kim and Frick, 2011).

Cognitive overload may have played a critical role in shaping students' perception of online assignments as being excessively difficult. An overwhelming majority (75.4\%) of students in the current study were enrolled in 16 or more online courses simultaneously during the spring semester. This tendency varies across academic majors, but in general, it reflects the fact that Japanese college freshmen tend to attend many classes per semester. As a result, they exhibit higher levels of fatigue (Ono, 2020). Based on this finding, we suggest that the need to be simultaneously enrolled in many online courses during the COVID-19 pandemic is one of the critical elements differentiating emergency online learning from conventional online learning. More empirical research on emergency online learning is needed, based on existing studies (Hartley, 1999; Morrison and Anglin, 2005; Tyler-Smith, 2006). We predict that the higher levels of cognitive overloadcaused by the need to enrol in many courses simultaneously-may negatively affect their motivation to perform coursework. This lack of motivation may be more prevalent in freshmen with little or no experience of online learning.

The results also showed that other factors, such as outside pressure, perceived lack of meaning, and lack of personal interest in the topic, seem to play a moderate role in causing students' decreased motivation, whereas fatigue, lack of feedback upon task completion, and perceived lack of material incentives for completing a given task (e.g. points awarded) were less frequently or rarely mentioned by the students. The diversity of approaches to instructional and assignment design taken by different instructors teaching different subjects in various departments could explain the inconsistency of these findings to other studies of Japanese online learners during the COVID-19 pandemic (Ono, 2020).

These results note that none of the motivation theories that informed this study had all the instruments necessary to fully explain the freshman motivation to work on assignments during online learning during the pandemic, 
which can be observed during micro- and macro-level analyses of student responses. For example, the micro-level analysis of individual comments (see Fig. 5) showed that the freshmen perception of motivating online assignments seems to have involved a rather complex set of psychological constructs discussed earlier. In other words, their narratives were not restrained by a single factor, instead they endorsed 'a variety of types of motivation simultaneously within a given context' (Hartnett, 2016, p. 128). Similarly, the macro-level analysis of multiple responses of the same assignment (see Fig. 6) shows that learners' motivation is produced by unique sets of factors in each individual case.

Based on this finding, it is crucial to apply a multifaceted approach to the analysis of factors related to motivation when examining learner motivation in both conventional and non-conventional circumstances (such as the current pandemic or some major crisis). One approach that the authors found particularly promising is the situation-dependent explanation of motivation (Hartnett, 2016; Turner and Patrick, 2008). From this perspective, it is helpful not to restrict one's approach to a simple dichotomous analysis of intrinsic versus extrinsic motivation of online task performance but instead to consider the influence of broader sets of factors, such as psychological (autonomy, utility, relevance), cognitive (information overload), social (relatedness, interaction), technological (synchronous, asynchronous), and environmental (crisis, uncertainty, isolation). Although this analytic strategy may look complex initially, it could eventually serve to calibrate instructional materials to address the learners' motivational needs better. In sum, the findings of this study are aligned with the proposition that self-determined motivation requires 'qualitatively differentiated learning experiences ... [that must] begin with the students, aligning what they learn (content), how they learn (processes), and the outcomes of their learning (products) with who they are' (Hartnett, 2016, p. 115). The study recommends that teachers deliberately and extensively employ strategies to enhance the motivational appeal of instructional materials and assignments, especially during emergencies.

\section{Conclusion, Limitations, and Directions for Future Research}

Instructional design and its effects on freshman motivation to learn is one of the critical issues in emergency online learning. The current study attempted to address this issue by focusing on the effects of online assignment design. By conducting a qualitative analysis, the authors examined the factors that influenced freshmen's motivation to perform effectively on online assignments and to determine which assignments were perceived as motivating. This study also shed light on the factors that influenced students' decreased motivation and disengagement, and which assignments were perceived as not motivating. The results allowed the researchers to discuss both theoretical and practical ramifications of instructional design for online learner motivation and engagement during the COVID-19 pandemic and beyond. The results have provided evidence that the instructional and learning design of emergency remote learning should take into consideration not only formal curricular aspects of 'what to learn' but also intricate considerations of how other social and physical factors (Green et al. 2020) influence student's motivation to be active in an online class by effectively addressing the question of 'how to learn'.

It should also be mentioned that this study had several limitations. Firstly, because this research examined an asynchronous online English reading course characterised by a comparatively higher volume of independent studies (e.g. reading and reflection), researchers should use caution when generalising the findings to other online learning environments requiring more extensive student-to-student and student-to-teacher interaction (e.g. presentation or
Fig. 5 Micro-level analysis of student responses

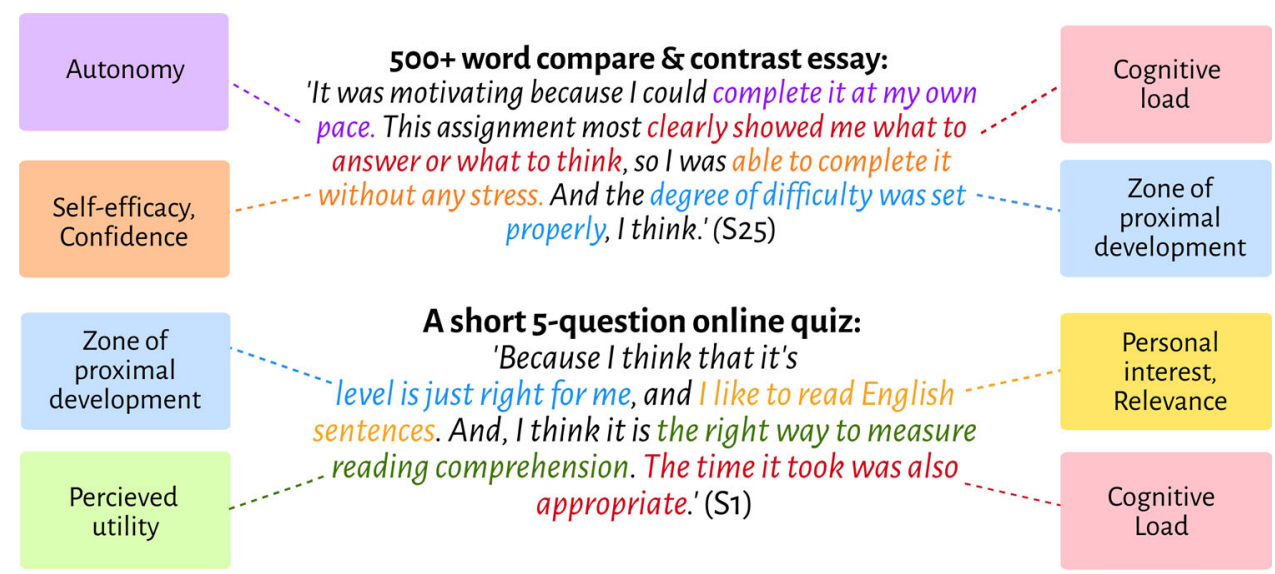




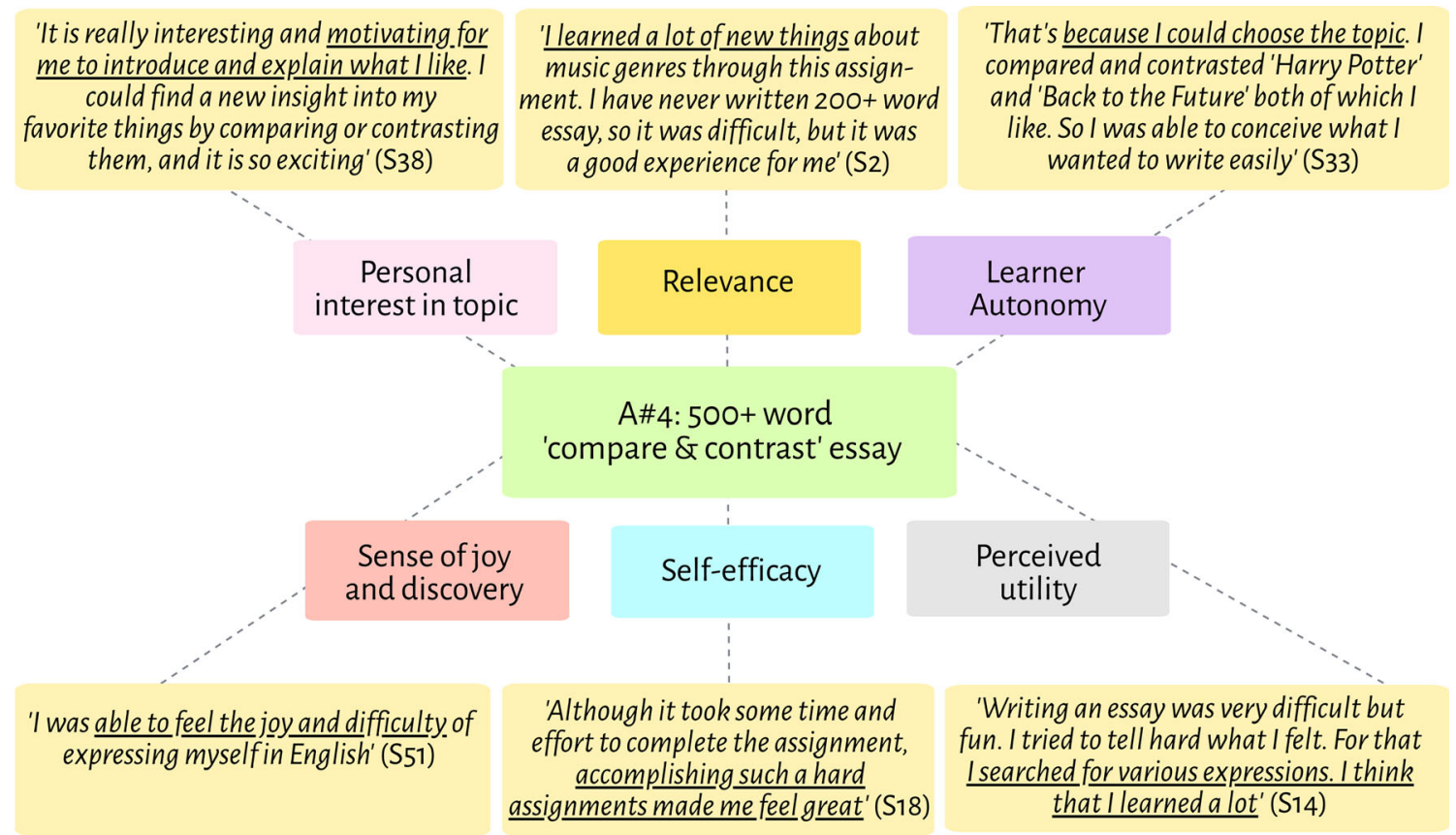

Fig. 6 Macro-level analysis of student responses

conversation skills courses). Future studies might shed light on this aspect.

Secondly, the present study involved groups of mainly first-year Japanese students, and thus, the sample may have been rendered homogeneous. To avoid generalisations based on the experiences of a single sample group, future studies might focus on how online assignment design affects motivation to learn across a diverse population of learners, including freshmen and sophomores as well as international and local students.

Thirdly, the timing of the research experiment was determined by the spread of COVID-19, the heightened social distancing measures, and when restrictions of movement were still in place in Japan. Presumably, most participants spent a great deal of time in their homes. Thus, their participation in the course as well as their responses to the post-course survey may have been influenced by a range of unique psychological and emotional factors related to the COVID-19 situation in Japan. Future studies could fill this gap by considering cases from other geographic locations as well as other emergency situations, such as motivation to learn online during major socio-political and economic crises, or during a natural disaster.

Acknowledgements The authors would like to thank the two anonymous reviewers for their helpful comments and suggestions.

Funding This research was supported by the Japan Society for the Promotion of Science (JSPS) KAKENHI Grant-in-Aid for Research Activity Start-up No.19K23334 and Grant-in-Aid for Scientific Research (C) No. 19K00903.

\section{Declarations}

Conflict of interest No potential conflict of interest was reported by the authors.Appendix

\section{Post-course Survey}

\section{Preamble}

Please take a few minutes and take this post-course survey. This survey is not graded, and your participation is voluntary. You have already received your course grade; thus, your survey responses cannot and will not affect your grades in any way; so please answer each question honestly and fully. Your answers will help me improve this online course to provide you with a better, more engaging learning experience in the next semester. Thank you for your time and stay safe!

1. Please provide your full class name (for example, English Reading Skills, Monday, period 3).

2. How many online courses per week did you attend during the past semester?

3. Please briefly describe your online learning experience over the past semester.

4. Out of all online courses that you took in the past semester, which course offered assignments that made you feel highly motivated and interested to complete? Why?

5. Out of all online course assignments that you took this semester within any subject, which assignments did not motivate you enough to complete? Why? 
6. Can you provide an example(s) of motivating and demotivating assignments?

7. On a 5-star level, how would you rate the English reading skills course you took this semester, in terms of course content and provided materials? $(1$ star $=$ not interesting at all $/ 5$ star $=$ very interesting $)$.

8. On a 5-star level, how would you rate your level of motivation when attending the English reading skills course in this semester? ( $1 \mathrm{star}=$ not motivated at all $/$ 5 star $=$ highly motivated throughout the course).

9. On a 5-star level, how would you rate your motivation when completing the assignments of the English reading skills course? $(1$ star $=$ not motivated at all $/ 5$ star = highly motivated throughout the course).

10. Which of the following eight assignments of the English reading skills course was the most interesting and motivating to you? (List of assignments follows).

11. Why was this assignment interesting and motivating to you? Please write your opinion in at least $30-50$ words.

12. Which of the following eight assignments of the English reading skills course was the least interesting and not motivating to you? (List of assignments follows).

13. Why was this assignment not interesting and least motivating to you? Please write your opinion in at least 30-50 words.

14. When taking the English reading skills course, which one of the following conditions has played the key role in your successful completion of any assignment? Multiple choices are as follows: (1) Level of difficulty (hard vs. easy); (2) The English skills needed (advanced vs. average); (3) Time to complete (too much time vs. quick to complete); (4) Instructions given (clear vs. not clear); (5) Personal interest in the topic (high vs. low); (6) Instructors feedback (instant vs. delayed); (7) Points awarded (many points vs. few points); (8) Chance to interact with classmates online (more vs. none); and (9) Other (please specify).

15. Did you read the feedback from your instructor for your completed assignment?

16. Did your instructor's feedback motivate you in any way when undertaking your next assignment?

17. It is likely that the English reading skills course (as all other University courses) will be taught online again in the Fall semester. In your view, should I change the way I teach it, or keep it as it is? Either way, please explain your preference.

18. What kind of assignment(s) would you personally like to see in this online course to make it more interesting and motivating?
19. Would you like to have more opportunities to interact with your classmates by doing virtual partner or team assignments?

20. (Optional) From your experience, which three of the following conditions influenced your personal motivation and interest, especially when taking any of the University online courses during the COVID-19 pandemic? Multiple choices are as follows: (1) Amount of sleep and rest; (2) Amount of physical exercise; (3) Quality of nutrition (healthy vs. junk food); (4) The number of subjects to be studied; (5) Information overload (including news); (6) Financial difficulties; (7) Personal problems; (8) Family situation; (9) Fatigue from a part-time job; (10) Fatigue from the use of Internet (SNS, YouTube, etc.); (11) Fatigue from staying at home whole day; (12) Lack of social life and new friends; and (13) Time management.

\section{References}

Abuhassna, H., Al-Rahmi, W. M., Yahya, N., Megat Zakaria, M. A. Z., Kosnin, A. B. M., \& Darwish, M. (2020). Development of a new model on utilizing online learning platforms to improve students' academic achievements and satisfaction. International Journal of Educational Technology in Higher Education. https://doi.org/10.1186/s41239-020-00216-z

Atkinson, J. W. (1957). Motivational determinants of risk-taking behavior. Psychological Review, 64, 359-72

Bandura, A. (1997). Self-efficacy: The exercise of control. Freeman.

Brophy, J. (2008). Developing students' appreciation for what is taught in school. Educational Psychologist, 43(3), 132-141

Burla, L., Knierim, B., Barth, J., Liewald, K., Duetz, M., \& Abel, T. (2008). From text to codings: Intercoder reliability assessment in qualitative content analysis. Nursing Research, 57(2), 113-117

Chen, Z., Jiao, J., \& Hu, K. (2021). Formative assessment as an online instruction intervention: Student engagement, outcomes, and perceptions. International Journal of Distance Education Technologies, $19(1), \quad 1-16$. https://doi.org/10.4018/ijdet.20210101.oa1

Dalby, D., \& Swan, M. (2018). Using digital technology to enhance formative assessment in mathematics classrooms. British Journal of Educational Technology, 36, 217-235

Deci, E. L., \& Ryan, R. M. (2000). The 'what' and 'why' of goal pursuits: Human needs and the self-determination of behavior. Psychological inquiry, 11, 227-268

Dörnyei, Z., \& Ushioda, E. (2011). Teaching and researching motivation. (2nd ed.). Pearson Education Limited.

Eccles, J. S., \& Wigfield, A. (2002). Motivational beliefs, values, and goals. Annual Review of Psychology, 53, 109-32

Eccles, J. S., \& Wigfield, A. (2020). From expectancy-value theory to situated expectancy-value theory: A developmental, social cognitive, and sociocultural perspective on motivation. Contemporary Educational Psychology, 61, Article 101859. https://doi.org/10.1016/j.cedpsych.2020.101859

Ferrer, J., Ringer, A., Saville, K., Parris, M. A., \& Kashi, K. (2020). Students' motivation and engagement in higher education: The 
importance of attitude to online learning. Higher Education. https://doi.org/10.1007/s10734-020-00657-5

Fryer, L., Bovee, N., \& Nakao, K. (2014). E-learning: Reasons students in language learning courses don't want to. Computers \& Education, 74, 26-36

Green, J. K., Burrow, M. S., \& Carvalho, L. (2020). Designing for transition: Supporting teachers and students cope with emergency remote education. Postdigital Science and Education, 2, 906-922. https://doi.org/10.1007/s42438-020-00185-6

Hartley, K. W. (1999). Media overload in instructional Web pages and the impact on learning. Educational Media International, $36(2), 145-150$

Hartnett, M. (2016). Motivation in online education. Springer.

Herrington, J., Reeves, T. C., Oliver, R., \& Woo, Y. (2004). Designing authentic activities in web-based courses. Journal of Computing in Higher Education, 16(1), 3-29

Hidi, S. E., Renninger, K. A., \& Northoff, G. (2019). The educational benefits of self-related information processing. In K. A. Renninger \& S. E. Hidi (Eds.), The Cambridge handbook of motivation and learning. (pp. 15-35). Cambridge University Press.

Hodges, C., Moore, S., Lockee, B., Trust, T., \& Bond, A. (2020). The difference between emergency remote teaching and online learning. EDUCAUSE Review. Retrieved August 5, 2020 from https://er.educause.edu/articles/2020/3/the-difference-betweenemergency-remote-teaching-and-online-learning

Hoskins, S. L., \& Van Hooff, J. C. (2005). Motivation and ability: Which students use online learning and what influence does it have on their achievement? British Journal of Educational Technology, 36, 177-192

Hsu, H. C. K., Wang, C. V., \& Levesque-Bristol, C. (2019). Reexamining the impact of self-determination theory on learning outcomes in the online learning environment. Education and Information Technologies, 24, 2159-2174

Hulleman, C. S., \& Barron, K. E. (2016). Motivation interventions in education: Bridging theory, research, and practice. In L. Corno \& E. M. Anderman (Eds.), Handbook of educational psychology. (3rd ed., pp. 160-71). Routledge, Taylor, and Francis.

Johnson, R., Stewart, C., \& Bachman, C. (2015). What drives students to complete online courses? What drives faculty to teach online? Validating a measure of motivation orientation in university students and faculty. Interactive Learning Environments, 23(4), 528-543

Josselson, R., et al. (2011). Narrative research constructing, deconstructing, and reconstructing story. In F. J. Wertz (Ed.), Five ways of doing qualitative analysis: Phenomenological psychology, grounded theory, discourse analysis, narrative research, and intuitive inquiry. (pp. 224-242). The Guildford Press.

Keller, J. M. (1983). Motivational design of instruction. In C. M. Reigeluth (Ed.), Instructional design theories and models: An overview of their current status.Lawrence Erlbaum.

Keller, J. M. (1987). Development and use of the ARCS model of instructional design. Journal of Instructional Development, $10(3), 2-10$

Kim, K., \& Frick, T. W. (2011). Changes in student motivation during online learning. Journal of Educational Computing Research, $44,1-23$

Laffey, J., Lin, G., \& Lin, Y. (2006). Assessing social ability in online learning environments. Journal of Interactive Learning Research, 17(2), 163-177

Leong, F. T. L., Bonz, M. H., \& Zachar, P (1997). Coping styles as predictors of college adjustment among freshmen. Counselling Psychology Quarterly, 10(2), 211-220.

LePine, J. A., LePine, M. A., \& Jackson, C. L. (2004). Challenge and hindrance stress: Relationships with exhaustion, motivation to learn, and learning performance. Journal of Applied Psychology, 89(5), 883-891

MacKinnon, D. P., Fairchild, A. J., \& Fritz, M. S. (2007). Mediation analysis. Annual review of psychology, 58, 593-614. https://doi.org/10.1146/annurev.psych.58.110405.085542

Martens, R. L., Gulikers, J., \& Bastiaens, T. (2004). The impact of intrinsic motivation on e-learning in authentic computer tasks. Journal of Computer Assisted learning, 20(5), 368-376

Martin, F., \& Bolliger, D. U. (2018). Engagement matters: Student perceptions on the importance of engagement strategies in the online learning environment. Online Learning, 22(1), 205-222. https://doi.org/10.24059/olj.v22i1.1092

McKenzie, W. A., Perini, E., Rohlf, V., Toukhsati, S., Conduit, R., \& Sanson, G. (2013). A blended learning lecture delivery model for large and diverse undergraduate cohorts. Computers and Education, 64, 116-126

Merrill, D. M. (2002). First principles of instruction. Educational Technology Research and Development, 50(3), 43-59

MEXT/Ministry of Education, Culture, Sports, Science and Technology of Japan. (2020). COVID-19: Information about MEXT's measures. Retrieved September 1, 2020 from https://www.mext.go.jp/en/mext_00006.html

Moos, D. C., \& Azevedo, R. (2008). Exploring the fluctuation of motivation and use of self-regulatory processes during learning with hypermedia. Instructional Science, 36(3), 203-231

Moos, D. C., \& Marroquin, E. (2010). Review: Multimedia, hypermedia, and hypertext: Motivation considered and reconsidered. Computers in Human Behavior, 26, 265-276

Morrison, G. R., \& Anglin, G. J. (2005). Research on cognitive load theory: Application to e-learning. Educational Technology Research and Development, 53(3), 94-104

Mudhovozi, P. (2012). Social and academic adjustment of first-year university students. Journal of Social Sciences, 33(2), 251-259.

O'Donoghue, J. J. (2020). In the era of COVID-19, a shift to digital forms of teaching in Japan. The Japan Times, 21 April 2020. Retrieved September 9, 2020 from https://www.japantimes.co.jp/news/2020/04/21/national/ traditional-to-digital-teaching-coronavirus/

Ono, Y., et al. (2020). Factors affecting Japanese students' fatigue in online foreign language presentation courses during the COVID19 pandemic. In H. R. So (Ed.), Proceedings of the 28th International conference on computers in education. (pp. 700-704). Asia-Pacific Society for Computers in Education.

Patall, E. A., Dent, A. L., Oyer, M., \& Wynn, S. R. (2013). Student autonomy and course value: The unique and cumulative roles of various teacher practices. Motivation and Emotion, 37, 14-32

Patall, E. A., \& Hooper, S. Y. (2019). The promise and peril of choosing for motivation and learning. In K. A. Renninger \& S. E. Hidi (Eds.), The Cambridge handbook of motivation and learning. (pp. 238-262). Cambridge University Press.

Patron, H., \& Lopez, S. (2011). Student effort, consistency, and online performance. Journal of Educators Online, 8, 1-11

Picciano, A. (2002). Beyond student perceptions: Issues of interaction, presence, and performance in an online course. Journal of Asynchronous Learning Networks, 6(1), 21-40

Pintrich, P. R., Meece, J., \& Schunk, D. H. (2014). Motivation in education: Theory, research, and applications. (4th ed.). Pearson Education Limited.

Podolskiy, A. (2012). Zone of proximal development. In N. M. Seel (Ed.), Encyclopaedia of the sciences of learning. Springer. https://doi.org/10.1007/978-1-4419-1428-6_3046

Rosenzweig, E. Q., Wigfield, A., \& Eccles, J. S. (2019). Expectancyvalue theory and its relevance for student motivation and learning. In K. A. Renninger \& S. E. Hidi (Eds.), The Cambridge handbook of motivation and learning. (pp. 617-644). Cambridge University Press. 
Rothes, A., Lemos, M. S., \& Gonçalves, T. (2014). Motives and beliefs of learners enrolled in adult education. Procedia. Social and Behavioral Sciences, 112, 939-948

Rovai, A. P., Ponton, M., Wighting, M. J., \& Baker, J. (2007). A comparative analysis of student motivation in traditional classroom and e-learning courses. International Journal on E-Learning, 6(3), 413-432

Ryan, R. M., \& Deci, E. L. (2000). Intrinsic and extrinsic motivations: Classic definitions and new directions. Contemporary Educational Psychology, 25(1), 54-67

Sansone, C., Fraughton, T., Zachary, J. L., Butner, J., \& Heiner, C. (2011). Self-regulation of motivation when learning online: The importance of who, why, and how. Education Technology Research and Development, 59, 199-212

Sasaki, M., \& Yamasaki, K. (2007). Stress coping and the adjustment process among university freshmen. Counselling Psychology Quarterly, 20(1), 51-67.

Japan Times. (2020). Shift to online classes leaves Japan's University teachers exhausted. May 24, 2020. Retrieved September 3, 2020 from https://www.japantimes.co.jp/news/2020/05/24/national/ university-teachers-japan-exhausted-online-classes/

Silverman, D. (2004). Qualitative research: Theory, Method and practice. (2nd ed.). Sage Publications.

Trautwein, U., Nagengast, B., Roberts, B., \& Lüdtke, O. (2019). Predicting academic effort: The conscientiousness $\times$ interest compensation (CONIC) model. In K. A. Renninger \& S. E. Hidi (Eds.), The Cambridge handbook of motivation and learning. (pp. 353-372). Cambridge University Press.

Tu, C.-H., \& McIsaac, M. (2010). The relationship of social presence and interaction in online classes. The American Journal of Distance Education, 16(3), 131-150

Turner, J. C., \& Patrick, H. (2008). How does motivation develop and why does it change? Reframing motivation research. Educational Psychologist, 43(3), 119-131
Tyler-Smith, K. (2006). Early attrition among first time E-learners: A review of factors that contribute to drop-out, withdrawal and non-completion rates of adult learners undertaking elearning programmes. Journal of Online Learning and Teaching, 2(2), $73-85$

UNESCO. (2020). COVID-19 impact on education/global monitoring of school closures caused by COVID-19. Retrieved September 3, 2020 from https://en.unesco.org/covid19/educationresponse

Usher, E. L. (2016). Personal capability beliefs. In E. Anderman \& L. Corno (Eds.), Handbook of educational psychology. (3rd ed., pp. 146-59). Taylor \& Francis.

Vygotsky, L. S. (1978). Mind in society: The development of higher psychological process. Harvard University Press.

Williamson, B., Eynon, R., \& Potter, J. (2020). Pandemic politics, pedagogies, and practices: Digital technologies and distance education during the coronavirus emergency. Learning, Media and Technology, 45(2), 107-114

Xie, K., DeBacker, T., \& Ferguson, C. (2006). Extending the traditional classroom through online discussion: The role of student motivation. Journal of Educational Computing Research, 34, 67-89

Zainuddin, Z., Shujahat, M., Haruna, H., \& Chu, S. K. W. (2020). The role of gamified e-quizzes on student learning and engagement: An interactive gamification solution for a formative assessment system. Computers and Education, 145, 103729. https://doi.org/10.1016/j.compedu.2019.103729

Zhang, F., \& Bae, C. L. (2020). Motivational factors that influence student science achievement: A systematic literature review of TIMSS studies. International Journal of Science Education, 42(17), 2921-2944

Publisher's Note Springer Nature remains neutral with regard to jurisdictional claims in published maps and institutional affiliations. 